\title{
Hepatitis B infection in Eastern Mediterranean Region: challenges and the way forward
}

\author{
Huma Qureshi ${ }^{1}$
}

In all the countries of the World Health Organization's (WHO) Eastern Mediterranean Region (EMR), hepatitis B infection is endemic [1]. In low-risk countries, hepatitis B infection occurs in teenagers and young adults as a result of risky behaviours. Effective vaccination, better blood screening and proper sterilization/disinfection has contributed considerably in its control [2]. In endemic countries, including EMR countries, however, the infection tends to occur in infants and children from maternal-fetal transmission, close contacts from persons nursing the infected patient's wounds and the percutaneous route (unsafe injections, improperly sterilized invasive medical devices and improperlyscreened blood transfusions) $[3,4]$. Unfortunately in endemic countries, the disease in children is generally unrecognized because the signs and symptoms are negligible. These cases are unlikely therefore to be recorded in the surveillance data. As a result, endemic countries bear the brunt of hepatitis B infection as adult chronic disease, cirrhosis and its complications and hepatocellular carcinoma [5].

According to $\mathrm{WHO}$ and the Centers for Disease Control and Prevention (CDC) [1], the major interventions that can control the spread of hepatitis B include: a) Hepatitis B vaccination (universal immunization of all neonates, catch-up vaccination of all children who have missed the universal vaccination and vaccination of high-risk groups); b) Safe blood transfusion; c) Injection safety; d) Infection control including hospital waste management; and e) Surveillance for new cases.

Routine infant immunization programmes will ultimately achieve a wide coverage and increased immunity in the population and hence prevent disease spread and the chronic complications of hepatitis B infection [6]. Reduction in the prevalence of hepatitis B infection has already been reported from many highly endemic countries after the launch immunization programmes [7-11].

Protective antibody titres ( > $10 \mathrm{IU}$ ) are achieved after vaccination which fall after some time but antibodies are boosted following exposure to hepatitis $B$ virus $[12,13]$. Antibody titres generally remain viable for 15 years and to date a booster dose is not recommended. Maternal-fetal transmission to infants born to HBsAg positive mothers can be drastically reduced with the administration of hepatitis B immune globulin (HBIG) and hepatitis B vaccine given at different sites [14] within 24 hours of birth [12].

The cost of treatment of hepatitis B infection and its complications is huge and cost-benefit studies show vaccination to be very cost-effective, even in low-endemic counties when compared with the treatment costs and life lost. However, although the cost of each hepatitis dose is less than US\$ 1 , with 3 doses the overall cost is higher when compared with the other 6 vaccines recommended by $\mathrm{WHO}$ and given through the Expanded Programme on Immunization (EPI) [12] and this is a concern of many developing countries.
While hepatitis B vaccine has been introduced into EPI in all countries of the Region except Somalia and South Sudan, only 14 countries give a dose at birth. Nonetheless, over $85 \%$ of infants born in the Region have received 3 doses of hepatitis B vaccine [3] although some countries are reporting low figures [15]. As well as infant immunization, WHO recommends vaccination of high-risk groups, such as health care workers; however, in most EMR countries health workers are either not vaccinated or not fully vaccinated $[16,17]$.

An issue of concern in EMR countries is the viability of the vaccine at high temperatures as in most EMR countries, temperatures in summer reach $40{ }^{\circ} \mathrm{C}$ and higher. Fortunately, the hepatitis B vaccine is thermostable and remains effective for 1 week at temperatures of $45^{\circ} \mathrm{C}$ and for 1 month at $37^{\circ} \mathrm{C}[12]$.

The challenges for hepatitis B vaccination in EMR are to achieve > 95\% coverage in all neonates and to administer catch-up vaccination to those not yet covered and adult vaccination of highrisk groups, such as health workers. Each country should examine the reasons for low coverage at birth and address the issues accordingly and implement catch-up vaccination at schools, work places and homes. High-risk groups in particular need to be identified, motivated and vaccinated.

For countries with unregulated blood banking, a national strategy should be implemented on a priority basis with standardization of testing kits. 
Unnecessary therapeutic injections should be discouraged by improving people's perception about injections.
Surveillance of hepatitis should be added in the health information and management system of EMR countries to identify new cases arising in the population as the ultimate aim is to stop emergence of new cases.

\section{References}

1. World Health Organization, Department of Communicable Diseases Surveillance Response. Hepatitis B. (http:// www.who.int/csr/disease/hepatitis/HepatitisB_whocdscsrlyo2002_2.pdf, accessed 2 July 2013).

2. André F. Hepatitis B epidemiology in Asia, the Middle East and Africa. Vaccine, 2000 18(Suppl. 1):S20-S22.

3. The growing threats of hepatitis $B$ and $C$ in the Eastern Mediterranean Region: a call for action (Technical paper presented at the Fifty-sixth Session of the WHO Regional Committee for the Eastern Mediterranean, 2009 (http://applications. emro.who.int/docs/EM_RC56_3_en.pdf, accessed 2 July 2013).

4. Qureshi $\mathrm{H}$ et al. Prevalence of hepatitis B and C viral infections in Pakistan: findings of a national survey appealing for effective prevention and control measures. Eastern Mediterranean Health Journal, 2010, 16(Suppl.):S15-S23.

5. Bosan A et al. A review of hepatitis viral infections in Pakistan. Journal of the Pakistan Medical Association, 2010, 60(12):10451058.

6. Niederau $\mathrm{C}$ et al. Long-term follow-up of HBeAg-positive patients treated with interferon alfa for chronic hepatitis B. New England Journal of Medicine, 1996, 334:1422-1427.

7. El-Magrahe $\mathrm{H}$ et al. Maternal and neonatal seroprevalence of Hepatitis B surface antigen (HBsAg) in Tripoli, Libya. Journal of Infection in Developing Countries, 2010, 4(3):168-170.

8. Reda $\mathrm{AA}$ et al. Epidemiologic evaluation of the immunity against hepatitis B in Alexandria, Egypt. European Journal of Epidemiology, 2003, 18:1007-1011.

9. Kafi-abad SA et al. Prevalence and trends of human immunodeficiency virus, hepatitis B virus, and hepatitis C virus among blood donors in Iran, 2004 through 2007. Transfusion, 2009, 49:2214-2220.

10. Yahyapour $\mathrm{Y}$ et al. Active-passive Immunization Effectiveness Against Hepatitis B Virus in Children Born to HBsAg Positive Mothers in Amol, North of Iran. Oman Medical Journal, 2011, 26:399-403.

11. Madani TA. Trend in incidence of hepatitis B virus infection during a decade of universal childhood hepatitis B vaccination in Saudi Arabia. Transactions of the Royal Society of Tropical Medicine and Hygiene, 2007, 101:278-283.

12. Mahoney FJ, Kane M. Hepatitis B vaccine. In: Plotkin SA, Orenstein WA, eds. Vaccines, 3rd ed. Philadelphia, WB Saunders Company, 1999:158-182.

13. Robinson WS. Hepatitis $B$ virus and hepatitis D virus. In: Mandell GL, Bennett JE, Dolin R, eds. Principles and practice of infectious diseases, 4th ed. New York, Churchill Livingstone, 1995:1406-1439.

14. Hollinger FB, Liang TJ. Hepatitis B Virus. In: Knipe DM et al., eds. Fields virology, 4th ed. Philadelphia, Lippincott Williams \& Wilkins, 2001:2971-3036.

15. Pakistan Demographic and Health Survey 2006-07. Islamabad, Pakistan, National Institute of Population Studies (NIPS) [Pakistan] and Macro International Inc., 2008:126 (http://www. healthkp.gov.pk/downloads/PDHS.pdf, accessed 2 July, 2013).

16. Bakry $\mathrm{SH}$ et al. Knowledge, attitude and practice of health care workers toward Hepatitis B virus infection, Sudan. International Journal of Risk \& Safety in Medicine, 2012, 24:95-102.

17. Yacoub R et al. Hepatitis B vaccination status and needlestick injuries among healthcare workers in Syria. Journal of Global Infectious Diseases, 2010, 2:28-34. 